\title{
NOTA SOBRE UM PROCEDIMENTO DE QUARTEAMENTO DE AMOSTRAS OBTIDAS COM ARMADILHAS DE SEDIMENTO UTILIZADAS EM ÁGUAS COSTEIRAS
}

\author{
C.A.F. SCHETTINI \\ CTTMar/UNIVALI
}

\begin{abstract}
RESUMO
Esta nota descreve um procedimento de quarteamento de amostras obtidas com experimentos com armadilhas de sedimento em águas costeiras para avaliar o fluxo vertical de material particulado em suspensão. $O$ procedimento consiste basicamente de agitação com agitador magnético e tomada de alíquotas com uma seringa, e foi desenvolvido devido à necessidade de se obter alíquotas representativas da amostra para a realização de análises destrutivas. A replicabilidade, estimada pela razão entre a massa sub-amostrada pelo volume de cada alíquota, demostrou a eficiência do método, apresentando um coeficiente de variação (desvio padrão:média) inferior à 0,1.
\end{abstract}

Palavras chave: (1) armadilhas de sedimento; (2) quarteamento.

\section{A NOTE ABOUT A QUARTERING PROCEDURE FOR SEDIMENT TRAP SAMPLES FROM COASTAL WATER EXPERIMENTS.}

\begin{abstract}
This note describes a procedure used for quarter samples acquired during sediment traps experiments in coastal waters. The procedure, which basically consists of stirring the sample with a magnetic device and getting aliquots with a syringe, was developed due the need to obtain representative aliquots from the sample to be used in destructive analysis. The replicability, estimated by the subsampled mass to the aliquot volume, showed the method efficiency, presenting a variation coefficient (standard deviation:mean) smaller than 0.1 .
\end{abstract}

Key words: (1) sediment traps; (2) quartering.

\section{INTRODUÇÃO}

A aplicação de armadilhas de sedimento é uma metodologia usualmente utilizada na avaliação de fluxos verticais nos oceanos (Iseki, 1981; Biscaye \& Anderson, 1994) e em áreas costeiras (Peinert et al., 1982; LundHansen et al, 1993). O princípio da utilização das armadilhas de sedimento consiste em criar um ambiente de baixa energia que possibilite capturar as partículas que estão sedimentando. A eficiência da armadilha em reter as partículas é uma função da sua geometria, bem como do escoamento onde se encontra, e.g., turbulência. $O$ desenho mais simples para armadilhas consiste de um tubo vertical com a extremidade inferior fechada. Estudos sobre a eficiência de reter partículas para experimentos em ambientes costeiros sugerem a relação 5:1 entre o comprimento e o diâmetro do tubo (Baker et al., 1988). Diversas configurações de armadilhas são pos- 
síveis, e o seu emprego pode ser associado tanto sobre estratégias amostrais eulerianas quanto lagrangeanas.

A partir da quantificação do material retido nas armadilhas, o fluxo de material particulado em suspensão é obtido pela razão entre a massa total retida pelo produto da área da boca com tempo de amostragem: [MASSA].[ÁREA] $]^{-1} \cdot[\text { TEMPO }]^{-1}$, ou kg. $\mathrm{m}^{-2} \cdot \mathrm{s}^{-1}$ no Sistema Internacional. A quantidade obtida usualmente é denominada de "taxa de sedimentação", porém o material amostrado no interior da armadilha pode ser originado também da ressuspensão de sedimentos de fundo (Lund-Hansen et al., 1993).

A obtenção da massa total retida nas armadilhas pode ser determinada pela filtração de todo material retido em filtro pré-pesado (método gravimétrico) ou pela eliminação da água da amostra por evaporação quando esta é acondicionada em um recipiente de massa conhecida. Em alguns casos, devido a heterogeneidade da amostra e a pouca massa disponível, a obtenção de alíquotas representativas (quartos) torna-se problemático. A presente nota descreve o procedimento utilizado por Schettini et al. (1997), Proença \& Schettini, (no prelo) e Schettini (submetido), no qual obtêm-se de maneira eficiente alíquotas da amostra de armadilhas.

\section{Características do Emprego das Armadilhas}

Um problema inerente ao uso de armadilhas é o consumo e produção de matéria orgânica no interior destas, sendo então utilizados venenos para fixar a amostra (soluções hipersalinas ou de formaldeído). Quanto menor for o fluxo vertical de material e maior for o tempo de amostragem, maiores serão os erros provenientes de processos biogeoquímicos (Lee, 1990). No entanto, Schettini et al. (1997), observou que para um período amostral curto (25 horas), e para condições de abundância de material retido, estes problemas podem ser desconsiderados.
O objetivo do emprego de armadilhas de sedimentos utilizadas por Schettini et al. (1997), Proença \& Schettini, (no prelo) e Schettini (submetido), foi avaliar o fluxo vertical de material particulado em zonas de cultivo de moluscos marinhos, e o sistema de armadilha utilizado foi adaptado de Larsson et al. (1986). Os experimentos consistiram do emprego das armadilhas por períodos de 25 horas, equivalente a dois ciclos completos de maré, sendo estas instaladas e retiradas com auxílio de mergulho autônomo, evitando-se ao máximo agitar os tubos. Estes foram imediatamente levados para laboratório para processamento, seguindo-se o procedimento descrito abaixo.

\section{MATERIAL \& MÉTODOS}

O procedimento para obtenção de alíquotas das amostras obtidas com armadiIhas em meio aquoso é resumido em cinco passos:

1 - Escoar o excesso de água da armadilha;

2 - Transferir para um Becker e completar para um volume determinado com água filtrada, e.g., $200 \mathrm{ml}$;

3 - Agitar a amostra com um agitador magnético o suficiente para manter todas as partículas em suspensão (isto é facilmente notado através da observação visual);

4 - Retirar a alíquota com uma seringa de precisão;

5 - Determinar a massa de material particulado na alíquota através de filtração com filtro de fibra de vidro de massa conhecida;

A fração da alíquota em relação à amostra total é obtida pela razão do volume da alíquota pelo volume ao qual o Becker foi completo. É importante ressaltar que deve 
haver um cuidado especial na retirada das armadilhas do ambiente e no seu transporte até o laboratório. Se houver agitação das armadilhas suficiente para ressuspender o material retido, as mesmas deverão ser armazenadas em ambiente refrigerado para que ocorra a decantação do material.

O escoamento da amostra e posterior complemento com água filtrada para um volume determinado proporciona uma lavagem eficiente da amostra para retirada de sais, sendo que estas são lavadas novamente durante a determinação gravimétrica. $O$ volume complementar de água deve ser proporcional à massa esperada. Nos experimentos realizados foram utilizados $200 \mathrm{ml}$. A diluição demasiada da amostra poderá acarretar no aumento de erros no procedimento da quantificação gravimétrica das alíquotas.

O passo de agitar a amostra objetiva estabelecer um sistema monofásico mantido pela turbulência do escoamento. O grau de turbulência deve ser proporcional ao máximo tamanho de partícula presente na amostra. As amostras obtidas por Schettini et al. (1997) consistiam de material fino juntamente com fragmentos de pelotas fecais de mexiIhões com dimensões de inferiores à $1 \mathrm{~mm}$, e o agitador magnético facilmente sustentou as partículas em suspensão. A intensidade de agitação foi incrementada continuamente até a verificação visual de não haver mais partículas junto ao fundo do Beker.

Após a homogeneização da amostra, a retirada da alíquota é realizada utilizandose uma seringa de precisão. No caso, utilizou-se uma ponteira de pipeta Eppendorf ${ }^{\mathrm{TM}}$ de $50 \mathrm{ml}$ previamente aferida com uma proveta. $O$ volume das alíquotas pode ser menor ou maior em função da quantidade de material coletado, bem como do número de réplicas e análises que se deseja realizar.

Para a realização da análise gravimétrica para determinação da massa contida nas alíquotas, foi utilizado filtro de fibra de vidro Millipore ${ }^{\mathrm{TM}}$ nos experimentos realizados. Entretanto, outro tipo de filtro também pode ser utilizado considerando-se as diferenças de porosidade e tipo de material, e.g., acetato de celulose. Os filtros foram secos durante 24 horas em estufa à $60^{\circ} \mathrm{C}$, e pesados em balança analítica de $10^{-4} \mathrm{~g}$ de precisão. As alíquotas foram filtradas à vácuo em kit de filtração de vidro com base porosa, sendo lavados com água filtrada pelo menos duas vezes.

\section{RESULTADOS}

A Tabela 1 mostra um exemplo da replicabilidade obtida com o procedimento descrito. A amostra em questão foi obtida durante um experimento para avaliar o fluxo vertical sob a região de cultivo de moluscos na Armação do Itapocory, SC. A amostra consistiu de um grande número de fragmentos de pelotas fecais juntamente com material particulado desagregado, provavelmente originado de ressuspensão ou da sedimentação do material particulado em suspensão. A razão entre a massa retida no filtro pelo volume da alíquota filtrada (concentração) normaliza os valores, apresentando uma média de 1,38

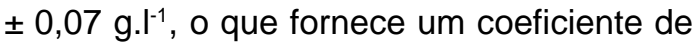
variação ( $C V$ = desvio padrão : média) de aproximadamente 0,05.

Durante os seis experimentos realizados por Proença \& Schettini (no prelo) e Schettini (submetido), foram realizados quarteamentos em 22 amostras obtidas com armadilhas de sedimento, apresentando um CV médio de 0,05. Destes quarteamentos, metade foram realizados com amostras obtidas sob o cultivo, com fragmentos de pelotas fecais mais material particulado desagregado, e a outra com amostras de uma estação de referência onde o material retido foi predominantemente de material particulado desagregado. Os CV's médios foram 0,05 e 0,04, respectivamente. Embora a diferença entre os coeficientes seja pequena, esta se deve pro- 
SCHETTINI: Quarteamento de Amostras de Armadilhas de Sedimentos.

Tabela 1: Dados referentes ao quarteamento de uma amostra coletada com armadilha de sedimento em fevereiro de 1996, sob uma região de cultivo de moluscos. $P_{\mathrm{PRÉ}}$ : massa do filtro pré filtragem; $P_{\mathrm{PÓs}}$ : massa do filtro pós filtragem; Dif.: diferença de massa; Dif./Vol.' 1000: concentração do material da alíquota, em g..$^{-1}$.

\begin{tabular}{ccccccc}
\hline \hline Alíquota & $\begin{array}{c}\text { Volume } \\
(\mathrm{ml})\end{array}$ & $\%$ Vol & $\begin{array}{c}\text { P PRÉ } \\
(\mathrm{g})\end{array}$ & $\begin{array}{c}\text { PPós } \\
(\mathrm{g})\end{array}$ & $\begin{array}{c}\text { Dif. } \\
(\mathrm{g})\end{array}$ & $\begin{array}{c}\text { Dif./Vol. } \\
\times 1000\end{array}$ \\
\hline 1 & 50 & 21,8 & 0,0877 & 0,1576 & 0,0699 & $\mathbf{1 , 4 0}$ \\
2 & 25 & 10,9 & 0,0874 & 0,1230 & 0,0356 & $\mathbf{1 , 4 2}$ \\
3 & 25 & 10,9 & 0,0888 & 0,1247 & 0,0359 & $\mathbf{1 , 4 4}$ \\
4 & 25 & 10,9 & 0,0878 & 0,1229 & 0,0351 & $\mathbf{1 , 4 0}$ \\
5 & 25 & 10,9 & 0,0871 & 0,1214 & 0,0343 & $\mathbf{1 , 3 7}$ \\
6 & 25 & 10,9 & 0,0900 & 0,1230 & 0,0330 & $\mathbf{1 , 3 2}$ \\
7 & 25 & 10,9 & 0,0873 & 0,1224 & 0,0351 & $\mathbf{1 , 4 0}$ \\
8 & 12,5 & 5,4 & 0,0883 & 0,1063 & 0,0180 & $\mathbf{1 , 4 4}$ \\
9 & 17 & 7,4 & 0,0869 & 0,1075 & 0,0206 & $\mathbf{1 , 2 1}$ \\
\hline Soma & 229,5 & 100 & & & 0,3175 & $\mathbf{1 , 3 8} \pm \mathbf{0 , 0 7}$ \\
\hline \hline
\end{tabular}

vavelmente à condição mais heterogênea das amostras que contém fragmentos de pelotas fecais.

O procedimento descrito nesta nota mostrou-se eficiente quando empregado sob as condições de grande quantidade de material retido nas armadilhas em um curto período de tempo, como as encontradas nos experimentos para avaliação de fluxos verticais em zonas de cultivo de moluscos. A sua aplicação em condições diferentes deve ser avaliado, e.g., armadilhas oceânicas, armadilhas de deriva, etc.

\section{AGRADECIMENTOS}

O autor agradece à Luís $\mathrm{A}$. Proença pela críticas ao manuscrito; à Gilberto Manzoni e Adriano Marenzi, por disponibilizarem as facilidades do Laboratório de Maricultura da Univali, e à Fernanda Borges, pelo auxílio no processamento das amostras.

\section{REFERÊNCIAS BIBLIOGRÁFICAS}

Baker, E.T.; Milburn, H.B.; Tennant, D.A. 1988.

Field assessment of sediment trap efficiency under varying flow conditions. J. Mar. Res., 46:573-592.

Biskaye, P.E. \& Anderson, R.F. 1994 Fluxes of particulate matter on the slope of the southern middle Atlantic Bigth: SEEP-II. Deep Sea Research II, 41(2/3):459-509.

Iseki, K. 1981. Particulate organic matter transport to the deep sea by salp fecal pellets. Marine Ecology, 5:55-60.

Larsson, U.; Blomqvist, S.; Abrahamsson, B. 1986. A new sediment trap system. Marine Ecology, 31:205-207.

Lee, C. 1990. Technical problems with the use of sediment traps - preservation, swimmers and leaching. In: Wassmann, P.; Heiskanen, A.-S.; Lindahl, O. (Eds.) Sediment trap studies in the nordic countries. Hanko, Tvärminne Zoological Station, p36-48.

Lund-Hansen, L.C.; Pejrup. M.; Valeur, J.; Jenses, A. 1993 Gross sedimentation rates in the North Sea - Baltic Sea transition: effects of stratification, wind energy transfer, and ressuspension.

Peinert, R.; Saure, A.; Stegmann, P.; Stienen, C.; Haardt, H. 1982 Dynamics of primary production and sedimentation in a coastal ecosystem. Netherlands Journal of Sea Research, 16:276-289. 
Proença, L.A. \& Schettini, C.A.F. (no prelo). Effect of shellfish culture on phytodetritus vertical fluxes in tropical waters - southern Brazil. Revista Brasileira de Oceanografia.

Schettini, C.A.F.; Resgalla Jr., C.; Kuroshima, K.N. 1997. Avaliação preliminar da taxa de sedimentação na região de cultivo de moluscos (Perna perna) na Enseada da Armação do Itapocoroy - SC. Notas Técnicas da Facimar, 1:1-8.

Schettini, C.A.F. (submetido). O papel do cultivo de moluscos na dispersão de sedimentos finos na Enseada da Armação do Itapocoroy. Notas Técnicas da Facimar. 